\title{
Shear-resistant hydrogels to control permeability of porous tubular scaffolds in vascular tissue engineering
}

\author{
Claudia Tresoldi, Daniela P. Pacheco, Elisa Formenti, Alessandro Filippo Pellegata, \\ Sara Mantero*, Paola Petrini \\ Dipartimento di Chimica, Materiali e Ingegneria Chimica, 'G. Natta' Politecnico di Milano, Piazza L. da Vinci, Milano, Italy
}

\section{A R T I C L E I N F O}

\section{Keywords:}

Alginate

Gelatin

Internal gelation

Porous tubular scaffolds

Mechanical conditioning

Leakproof

Bioreactors

\begin{abstract}
A B S T R A C T
Aiming to perfuse porous tubular scaffolds for vascular tissue engineering (VTE) with controlled flow rate, prevention of leakage through the scaffold lumen is required. A gel coating made of $8 \% \mathrm{w} / \mathrm{v}$ alginate and $6 \% \mathrm{w} / \mathrm{v}$ gelatin functionalized with fibronectin was produced using a custom-made bioreactor-based method. Different volumetric proportions of alginate and gelatin were tested (50/50, 70/30, and 90/10). Gel swelling and stability, and rheological, and uniaxial tensile tests reveal superior resistance to the aggressive biochemical microenvironment, and their ability to withstand physiological deformations $(\sim 10 \%)$ and wall shear stresses (5-20 dyne $/ \mathrm{cm}^{2}$ ). These are prerequisites to maintain the physiologic phenotypes of vascular smooth muscle cells and endothelial cells (ECs), mimicking blood vessels microenvironment. Gels can induce ECs proliferation and colonization, especially in the presence of fibronectin and higher percentages of gelatin. The custom-designed bioreactor enables the development of reproducible and homogeneous tubular gel coating. The permeability tests show the effectiveness of tubular scaffolds coated with 70/30 alginate/gelatin gel to occlude wadding pores, and therefore prevent leakages. The synthesized double-layered tubular scaffolds coated with alginate/gelatin gel and fibronectin represent both promising substrate for ECs and effective leakproof scaffolds, when subjected to pulsatile perfusion, for VTE applications.
\end{abstract}

\section{Introduction}

Cardiovascular diseases (CVDs) represent the leading cause of death worldwide (54\%), exceeding the deaths related with cancer $[1,2]$. Despite its high incidence, the current clinical treatments of CVDs, especially related to the need of substitutes for small-caliber vessels $(<6 \mathrm{~mm})$, suffer from severe limitations, including thrombogenicity and hemodynamic disturbances for compliance mismatch, as well as a shortage of autologous vessels [3]. Vascular tissue engineering (VTE) aims to develop functional small-caliber vessels, thus facing the complexity of their physiological structure [4-7]. Although still inspired to a simplified view, the design of either the substrate or the biomechanical stimuli should render the intrinsic duality of native vessels. Vascular smooth muscle cells (VSMCs) and endothelial cells (ECs) of the tunica media and intima, respectively, have different requirements for growth and this represents a key morphological and functional characteristic of native vessels. Thus, both luminal and outer layers of a vascular scaffold should support the adhesion of the different cells, while the degradation of the different layers should be consistent with the different cell growth kinetics [8-11]. Engineering gradients, also in vascular tissue engineering, is of outmost importance [12]. The possibility to process the proper polymeric substrate is a key feature to reproduce the architecture of blood vessels, where VSMCs and ECs are anatomically separated but functionally linked [5]. From this point of view, the necessity of grading the porosity of the three-dimensional tubular scaffold is also connected with the morphological requirements to improve VSMCs infiltration and extracellular matrix production, as well as the creation of a confluent luminal layer by ECs $[10,13,14]$.

Moreover, both types of vascular cells require biomechanical and biochemical stimuli to express their correct phenotype. When in vivo, VSMCs are continuously exposed to a maximum cyclic strain $\left(\varepsilon_{\text {circ }}\right)$ of around $10 \%$, while ECs and their progenitors (EPCs) are subjected to a fluid wall shear stress (WSS) in the range of 5-20 and 0.1-2.5 dyne/ $\mathrm{cm}^{2}$, respectively, due to pulsatile blood flow [5]. Cyclic strain aligns VSMCs in a circumferential direction and preserves their contractile phenotype; WSS addresses ECs to dispose longitudinally to the fluid direction and to keep their quiescent state and anti-inflammatory function, therefore creating a functional endothelial monolayer

\footnotetext{
* Corresponding author.

E-mail address: sara.mantero@polimi.it (S. Mantero).
} 
[15-18]. Thus, pulsatile perfusion is often adopted as an in vitro mechanical stimulus, using perfusion bioreactors on tubular scaffolds with seeded VSMCs in the external side and ECs in the lumen.

The selection of suitable scaffolds is of outmost importance. The simplest scaffolds mostly used as vascular grafts include decellularized swine arteries [19] and umbilical arteries or veins [8,20], owing to their comparable mechanical properties to those of native tissue $[21,22]$, neglectable or low porosity [23], and high EC-adhesive properties [21]. As drawbacks, these scaffolds impair VSMC infiltration, making the re-cellularization process hard and time-dispersive [19]. Moreover, decellularized biological tissues do not overcome the availability issue, while synthetic scaffolds offer favorable advantages, as higher reproducibility and both controlled microstructure [24] and degradation rate $[25,26]$. On one hand, porous scaffolds able to promote VSMCs colonization from the external side towards the lumen are required $[27,28]$. On the other hand, perfusion requires an impermeable luminal surface so that EPCs and ECs undergo controlled physiological WSS preventing fluid leakage throughout scaffold pores. In addition, the luminal surface of scaffolds should promote endothelial adhesion to enable EPCs and ECs to produce a confluent and stable monolayer, also when subjected to a fluid flow imposed by perfusion. This capability could be tackled by tuning porosity properties of the tubular scaffold (e.g. nanoporosity $v s$ microporosity) [10,29-31] and by means of chemical modifications with specific peptides that promote EC adhesion on the luminal surface of the tubular scaffold [17,32].

Among different materials, gelatin, derived from collagen hydrolysis, demonstrated to be suitable for tissue engineering purposes, including vascular tissue engineering [33-35], although being of animal origin, safety issues must be properly addressed following the pertinent regulations [36]. In this work, we employed alginate to control the coating process and the final properties of the scaffold. The crosslinking of alginates holds a huge flexibility in the design of multiple structures, by controlling the calcium ions, leading to the formation of the "eggbox junctions" [37-40] where the ionic complexation is synergistic to the formation of the egg-box junctions, thus allowing the fine tuning of mechanical properties of gels and the production of different forms of the hydrogels, 3D structures for cell cultures, injectable hydrogels, stiffness-controlled cell microenvironments [41-43].

In this work, a luminal coating made of alginate (Alg) and gelatin (Gel) further functionalized with fibronectin (Fn) is proposed for tubular porous scaffolds, through a novel experimental method consisting on a custom-made bioreactor. The gel coating is envisioned to (1) improve EC adhesion and proliferation, (2) maintain the luminal and external surfaces anatomically separated, but functionally linked, (3) provide two biodegradability levels of the bilayered scaffold, the first short-term to promote cell adhesion and the second middle-term to provide a porous guide for tissue ingrowth and (4) prevent leakage from the internal lumen, thus also allowing the control of the biomechanical stimuli.

\section{Materials and methods}

\subsection{Synthesis of alginate/gelatin gels}

Gels made of $8 \%(\mathrm{w} / \mathrm{v})$ alginate (Alg) and $6 \%(\mathrm{w} / \mathrm{v})$ gelatin $(\mathrm{Gel})$ were prepared following the ionotropic crosslinking process $[44,45]$. Different proportions of $\mathrm{Alg}$ and Gel were tested, including 50/50, 70/ 30 , and $90 / 10 \mathrm{v} / \mathrm{v}$, and further functionalized with fibronectin (Fn) $(50 / 50+\mathrm{Fn}, 70 / 30+\mathrm{Fn}$, and 90/10 + Fn). Briefly, alginic acid from brown algae Alg ( $8 \% \mathrm{w} / \mathrm{v})$ (A7003, Sigma Aldrich, batch number MKBJ0727V) and type-B Gel from bovine skin (6\% w/v) (G9391, Sigma Aldrich, batch number SLBM7200V) were separately dissolved in distilled water $\left(\mathrm{dH}_{2} \mathrm{O}\right)$ under magnetic stirring, either at room temperature (RT) or at $40^{\circ} \mathrm{C}$, respectively. Afterward, Alg and Gel were mixed in the aforementioned proportions until reaching a homogenous solution. Fnfunctionalized gels were obtained by adding $5 \mu \mathrm{g} / \mathrm{ml}$ of Fn (F0895,
Sigma Aldrich) to the Alg/Gel solution. Then, $50 \mathrm{mM}$ calcium carbonate $\left(\mathrm{CaCO}_{3}, \mathrm{C} 4830\right.$, Sigma Aldrich) and $10 \% \mathrm{w} / \mathrm{v} \mathrm{D-}(+)$-gluconic acid $\delta$ lactone (GDL, G4750, Sigma Aldrich) were subsequently mixed to Alg/ Gel solutions for internal gelation and left to react overnight at $4{ }^{\circ} \mathrm{C}$ (Supplementary Fig. S1). Finally, to improve shear stability, $0.1 \mathrm{M}$ calcium chloride $\left(\mathrm{CaCl}_{2}, 499609\right.$ Sigma Aldrich) was added for $10 \mathrm{~min}$ at RT for external crosslinking of the gels. Finally, the obtained gels were washed twice with culture medium (for medium composition, paragraph 2.2.4) for $10 \mathrm{~min}$ each.

For the synthesis of sterile gels, both Gel and Alg powders were disinfected using $100 \%$ ethanol (EtOH) for $1 \mathrm{~h}$ (four washing steps, 15 min each), and dried in sterility conditions until constant weight.

\subsection{Characterization of alginate/gelatin gels}

Under the hypothesis that Fn functionalization does not affect gel properties, but instead has impact over cellular behavior, physicochemical characterization of the developed gels was conducted on $\mathrm{Alg} /$ Gel (pure) gels [17].

\subsubsection{Stability and swelling tests}

Alg/Gel gels $(\varnothing=20 \mathrm{~mm}$, thickness $=2 \mathrm{~mm}$ ) were incubated with culture medium $\left(1 \mathrm{ml}\right.$ per gel) at $37^{\circ} \mathrm{C}$ with $5 \% \mathrm{CO}_{2}$. For each gel typology, the water content was calculated as the percent wet/wet weight variation (Eq. (1)):

$\Delta w_{\text {wet } / \text { wet }}[\%]=\frac{w_{\text {wet }}(t)}{w_{\text {wet }}(0)} \cdot 100$

The percent dry/dry weight variation was calculated (Eq. (2)).

$\Delta w_{d r y / d r y}[\%]=\frac{w_{d r y}(t)}{w_{d r y}(0)} \cdot 100$

The measurements were made in triplicate. The analyzed time points include $1,3,7,14$, and 21 days.

\subsubsection{Rheological tests}

The rheological properties of the different formulations of $\mathrm{Alg} / \mathrm{Gel}$ gels were determined using the AR-1500ex (TA Instruments, USA) rheometer coupled to a parallel-plated $(\varnothing=20 \mathrm{~mm})$ and fixed gap between the lower and upper plates of $2 \mathrm{~mm}$. Rheological tests were performed at $37^{\circ} \mathrm{C}$ under frequency sweep (from 0.1 to $100 \mathrm{~Hz}$ ), applying a force of $5 \mathrm{~Pa}$; torque sweep was from $1 \mu \mathrm{N} \cdot \mathrm{m}$ to $100 \mu \mathrm{N} \cdot \mathrm{m}$. The storage modulus $\left(\mathrm{G}^{\prime}\right)$ and the loss modulus $\left(\mathrm{G}^{\prime \prime}\right)$ of each gel formulation were obtained using the software TRIOS (TA Instruments - Thermal Analysis Instruments).

The shear stress $(\tau)$ induced by the torque on gels during the test was calculated (Eq. (3)) [46]:

$\tau\left[\right.$ dyne $\left./ \mathrm{cm}^{2}\right]=\frac{3 \cdot T}{2 \pi \cdot r^{3}}$

where $T$ is the torque applied by the upper plate of the rheometer and $r$ is the radius of the upper plate. The estimation of $\tau$ provides the first information about the ability of the gel to withstand to shear stresses at the gel-fluid interface before fracture.

Measurements were performed in triplicate after $2 \mathrm{~h}, 3,7$, and 14 days, for each type of gels $(\varnothing=20 \mathrm{~mm}$, thickness $=2 \mathrm{~mm})$.

Rheological tests were also carried out on Fn-functionalized gels with or without endothelial cells following the protocol described in section 2.2.4 Direct Cytotoxicity Tests. The same time points were investigated, considering gels without cells as control.

\subsubsection{Uniaxial tensile tests}

The ability of the gel to resist tensile deformation up to $10 \%$, uniaxial fracture tests (Fig. 1A-B) was evaluated using the MTS Synergie $200 \mathrm{H}$ (Helmut Singer Elektronik Vertriebs $\mathrm{GmbH}$ ) testing machine. Rectangular samples $(l=2.5 \mathrm{~cm}, \mathrm{~h}=0.5 \mathrm{~cm}$, thickness $=2 \mathrm{~mm})$ of 

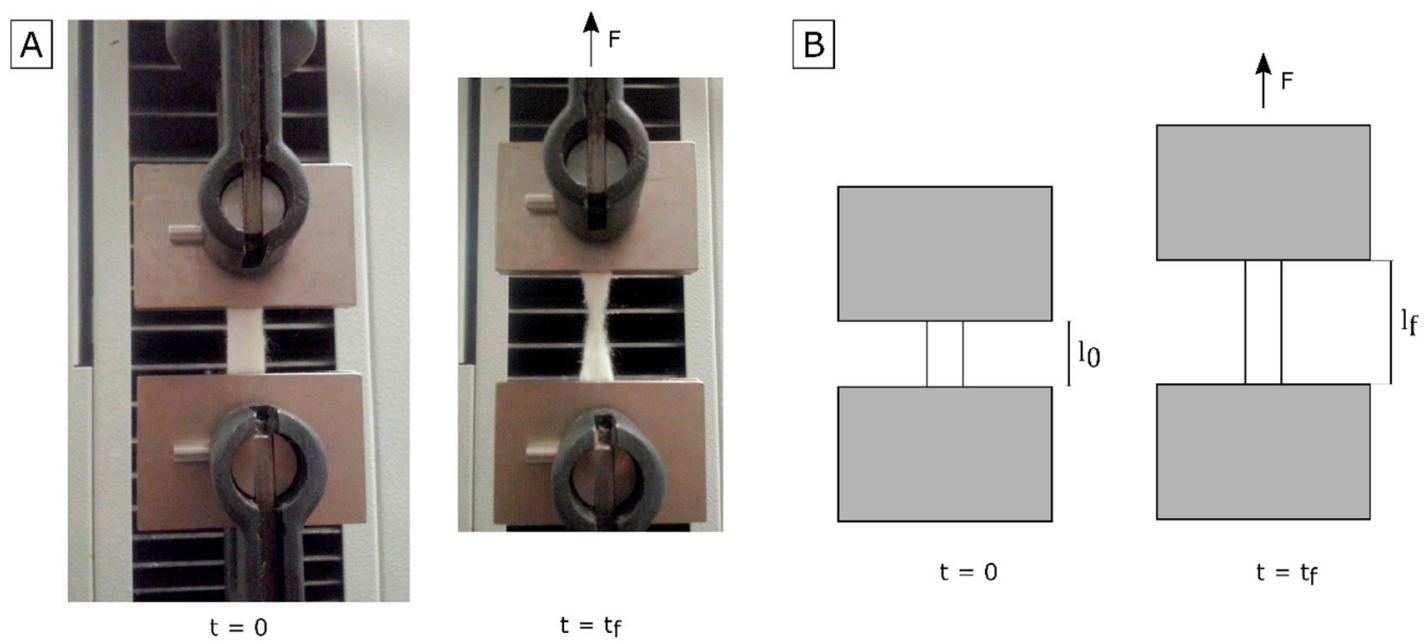

C

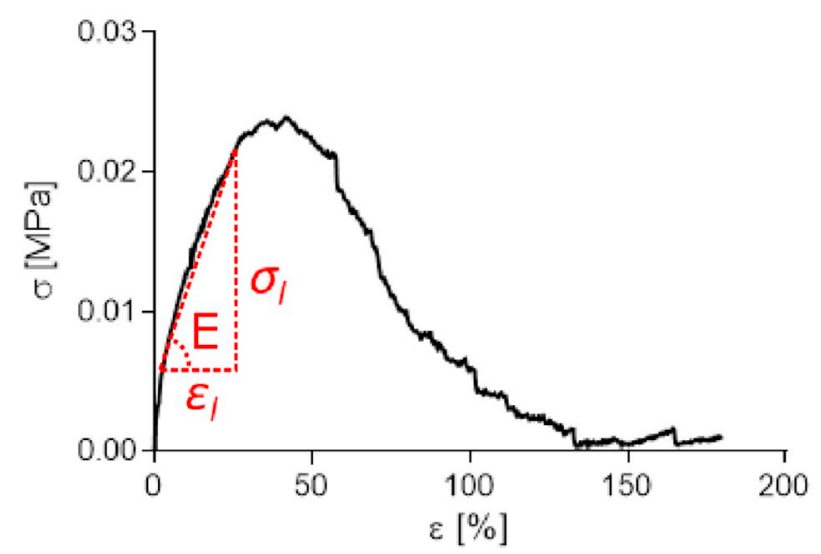

Fig. 1. Uniaxial tensile test. (A) Experimental setup and (B) its representation. $t=0$ is the initial configuration and $l_{0}$ is the initial length of the sample within the two machine holders; $t=t_{f}$ is the configuration reached by the sample with a length $l_{f}$ after the fracture. (C) Uniaxial tensile test. Representative $\sigma / \varepsilon$ curve of the mechanical behavior of coated wadding.

needle-punched wadding in synthetic fibers (Ortovat ${ }^{\circledR}{ }^{\circledR}$ ) were uniformly coated with the 50/50, 70/30, and 90/10 Alg/Gel gels (thickness $=2 \mathrm{~mm}$ ); wet pure wadding was considered as control.

A pre-load of $0.01 \mathrm{MPa}$ and a deformation speed of $1 \% l_{0}$ were imposed, where $l_{0}$ represented the length of the sample within the two machine holders (Fig. 1B). Data acquisition frequency was $100 \mathrm{~Hz}$. All the tests were performed under wet conditions to simulate the culture conditions of gels.

Young's modulus (Fig. 1C) was calculated in the linear region of each analyzed sample, as follow:

$E[M P a]=\frac{\sigma_{l}}{\varepsilon_{l}}$

where $\sigma_{l}$ and $\varepsilon_{l}$ are stress and deformation in the linear region.

Starting from the fracture elongation $\left(l_{f, g}\right)$ in correspondence of the gel fracture, the gel ultimate deformation $\left(\varepsilon_{\mathrm{f}, \mathrm{g}}\right)$ was calculated according to the Eq. (5):

$\varepsilon_{f, g}[\%]=\frac{l_{f, g}-l_{0}}{l_{0}}$

\subsubsection{Cell tests}

Direct cytocompatibility tests were performed on $\mathrm{Alg} / \mathrm{Gel}$ gels under static culture conditions using EA.hy926 cell line. Different formulations of $\mathrm{Alg} / \mathrm{Gel}$ with or without Fn were tested; 50/50, 70/30, and 90/ $10 \mathrm{v} / \mathrm{v}(\varnothing=4 \mathrm{~mm}$, thickness $=2 \mathrm{~mm})$ were produced using sterile components under sterile conditions (section 2.1 Synthesis ofalginate/ gelatingels). As a control, decellularized swine artery (DSA) was chosen as a positive control [21].

All samples were preconditioned overnight with Dulbecco's Modified Eagle Medium (DMEM 5671, Sigma Aldrich), added with 10\% Fetal Bovine Serum (F7524, Sigma Aldrich), 1\% HEPES (H3375, Sigma Aldrich), 1\% Sodium Pyruvate (P2256, Sigma Aldrich), 1\% L-Glutamine (G7513, Sigma Aldrich), and 1\% Penicillin-Streptomycin (P0781, Sigma Aldrich). EA.hy926 (seeding density $=2.5 \cdot 10^{5} \mathrm{cell} / \mathrm{cm}^{2}$ ) were seeded on the scaffolds. DMEM was changed every 3 days. At each timepoint $\left(1,7\right.$, and 14 days) viability assay (Alamar Blue $\left.{ }^{\circledR}\right)$, DNA quantification and optical investigation (optical microscope) were performed in triplicate.

Viability test: cell viability was evaluated by resazurin colorimetric assay (Alamar Blue ${ }^{\circledR}$, Serotec Ltd., Kidlington, Oxford, UK) at different time-points. Briefly, Alamar Blue ${ }^{\circledast}$ solution was diluted in 1:10 ratio in DMEM. For the direct cytotoxicity investigation, $500 \mu \mathrm{l}$ of this solution was further added to each sample and incubated for $4 \mathrm{~h}$. Supernatant fluorescence was measured at $590 \mathrm{~nm}(\lambda=510 \mathrm{~nm}$ as the reference wavelength) using the Multifunction Tecan spectrophotometer (GENios Plus).

DNA quantification: the total amount of DNA was quantified as described. Samples were immersed in cell digestion buffer at $55^{\circ} \mathrm{C}$ overnight with 0.005 volume proteinase $\mathrm{K}$, followed by treatment with sodium acetate $\mathrm{pH} 5.2$ to remove protein fraction. The supernatant was suspended in $98 \%$ and $70 \%$ ethanol, and centrifuged; the resulting DNA pellet was rehydrated in $\mathrm{dH}_{2} \mathrm{O}$. Total DNA was estimated using SYBR ${ }^{\circledast}$ Green (S9430, Sigma-Aldrich), with a calibration curve obtained from 
salmon sperm DNA (500 ng/ $\mu \mathrm{l})$. Fluorescence at $535 \mathrm{~nm}$ of each DNA sample (in triplicate) was measured by Tecan spectrophotometer. The cell number was estimated considering an average DNA quantity of $7 \mathrm{pg} /$ cell [47].

Optical analyses: Gels were observed at the fluorescent microscope BX51WI (Olympus Corporation) under white light beam. Photographs were captured through a detector U-RFL-T (Olympus Corporation) and acquired at a magnification of $40 \times$ using the software AnalySIS docu (Olympus Soft Imaging Solutions).

Statistical analyses: results of at least three independent experiments were expressed as mean \pm standard deviation. Two-way and multivariate analysis of variance (ANOVA) tests with Tukey's multiple comparisons were performed using GraphPad Prism software for Windows (GraphPad Software, Inc.). Unpaired $t$-test with Welch's correction and Kruskal-Wallis test were performed to compare viability and estimated cell number of gel with and without Fn and of DSA. A significance level of p-value $<0.05$ was applied.

\subsection{Production of the tubular alginate/gelatin coating}

The tubular Alg/Gel coating was obtained by modifications of the InBreath $^{\circledast}$ bioreactor [48], using the design software Solid Edge ST8 (Siemens). The custom-made bioreactor (Fig. 2) allowed the symmetric injection of the gel through the lateral accesses, the housing of tubular scaffolds with variable length and diameter, less or equal to $5 \mathrm{~mm}$.

Using this bioreactor-based method, the gels (50/50, 70/30, and $90 / 10 \mathrm{v} / \mathrm{v}$ ) were formed on the luminal surface of Ortovatt ${ }^{\circledast}$ wadding, in triplicate. After polymers injection using a Luer-lock syringe, the $\mathrm{Alg} / \mathrm{Gel}$ coated structures were formed into the bioreactor under longitudinal rotation $(5 \mathrm{rpm})$ following overnight internal gelation at $4{ }^{\circ} \mathrm{C}$. Subsequent injection of $\mathrm{CaCl}_{2}$ allowed surface crosslinking. Thus, the structure was removed from the mandrel. The uniform distribution of the gel on the wadding substrate was investigated using the WILD M8 stereomicroscope (Heerbrugg, Switzerland) at $20 \times$ magnification.

\subsection{Permeability tests on tubular $70 / 30 \mathrm{Alg} / \mathrm{Gel}$ coated wadding}

A flow rate of $200 \mathrm{ml} / \mathrm{min}$ was imposed through a perfusion circuit made of an open-air reservoir, two peristaltic pumps (code number 702027, serial number B-89653, Harvard Apparatus, USA), and the bioreactor block housed the scaffold. The perfusing fluid was $6 \%(\mathrm{w} / \mathrm{v})$ dextran from Leuconostoc (MW 70,000, 31390-100G, Sigma-Aldrich), reaching a viscosity of $0.003 \mathrm{~Pa} \cdot \mathrm{s}$ [8]. The fluid flow leaked through the lateral surface of the scaffold $\left(v_{\text {fol }}\right.$ fluid $)$ was measured on tubular $70 / 30$ $\mathrm{Alg} / \mathrm{Gel}$ coated wadding $(\varnothing=5.000 \mathrm{~mm}, \quad$ th $=3.650 \mathrm{~mm}$, $1=6.500 \mathrm{~mm})$. Pure wadding $(\varnothing=5.000 \mathrm{~mm}, \quad$ th $=1.650 \mathrm{~mm}$, $1=6.500 \mathrm{~mm}$ ) was considered as negative control, while DSA (carotid) $(\varnothing=3.000 \mathrm{~mm}$, th $=0.674 \mathrm{~mm}, 1=6.500 \mathrm{~mm}$ ), and tubular electrospun pure silk fibroin $(\varnothing=3.5 \mathrm{~mm}$, th $=0.300 \mathrm{~mm}, 1=6.500 \mathrm{~mm}$, produced by Leonardino s.r.l.) were selected as positive references, since they are commonly used for VTE applications [49,50].

The permeability coefficient for each scaffold was calculated according to Darcy's law, as follow [51]:

$K_{\text {Darcy }}=\frac{\mu}{\Delta P} \cdot \frac{t h}{A} \cdot Q$

where $K_{\text {Darcy }}$ is the permeability coefficient, $\mu$ is the viscosity of the perfusing fluid equal to $0.003 \mathrm{~Pa} \cdot \mathrm{s}, \Delta P$ is the transmural pressure difference equal to $16.25 \mathrm{mmHg}$, th is the thickness of the structure wall, and $Q$ is the flow though the inner lateral surface $A$, corresponding to vol $_{\text {fluid. }}$.

\section{Results}

Different formulations of $\mathrm{Alg} / \mathrm{Gel}$ gels were produced by ionic crosslinking due to $\mathrm{Ca}^{2+}$ ions. $\mathrm{Ca}^{2+}$ ions are progressively released from $\mathrm{CaCO}_{3}$ as $\mathrm{pH}$ decreases by lactone hydrolysis. To optimize gel composition considering the aim to produce a coating able to withstand to biochemical and biomechanical conditions typical of blood vessels, $\mathrm{Alg}$ and Gel were mixed at different volumetric percentages, (50/50, $70 / 30$, and $90 / 10 \mathrm{v} / \mathrm{v}$ ) and the respective physicochemical properties were further assessed.

\subsection{Characterization of alginate/gelatin gels}

\subsubsection{Stability and swelling tests}

The swelling of the different gels (Fig. 3A) showed an initial weight increase (about 25\%) due to DMEM absorption, then retained their weight, with no differences $(\mathrm{p}<0.05)$ among the three different formulations. Solid content (Eq. (2)) fluctuated about the mean initial value up to 21 days, independently of the hydrogel composition. This result indicates that gels do not reduce their solid content when in contact with DMEM, under culture conditions $\left(37^{\circ} \mathrm{C}\right.$ and $\left.5 \% \mathrm{CO}_{2}\right)$ (Fig. 3B).

\subsubsection{Rheological tests}

Frequency sweep tests indicated that all gels presented a gel-like behavior, with $G^{\prime}>G^{\prime \prime}$. The gel properties did not vary with frequency from 0.1 to $10 \mathrm{~Hz}$ (Fig. 4A). Gels containing Gel had a different rheological behavior, with lower values of $\mathrm{G}^{\prime}$ for $50 / 50 \mathrm{Alg} / \mathrm{Gel}$ than $70 / 30$ and 90/10 Alg/Gel gels, while G" was lower for 70/30 and 50/50 than 90/10 Alg/Gel gels ( $\mathrm{p}>0.05$ ) (Fig. 4B and Supplementary Fig. S4). The higher the concentration of $\mathrm{Alg}$, the higher is the resistance of $\mathrm{Alg}$ chains to uncoil and the thicker is the resulting gel.

Interestingly, a decrease in $\mathrm{G}^{\prime}$ (and G", Supplementary Fig. S4) was visible since the third day of culture with EA.hy926 cells (Fig. 4C). Rheological properties of 90/10 Alg/Gel gels were less affected by the culture conditions (Fig. 4B). Moreover, $\mathrm{G}^{\prime}$ increased upon incubation: in

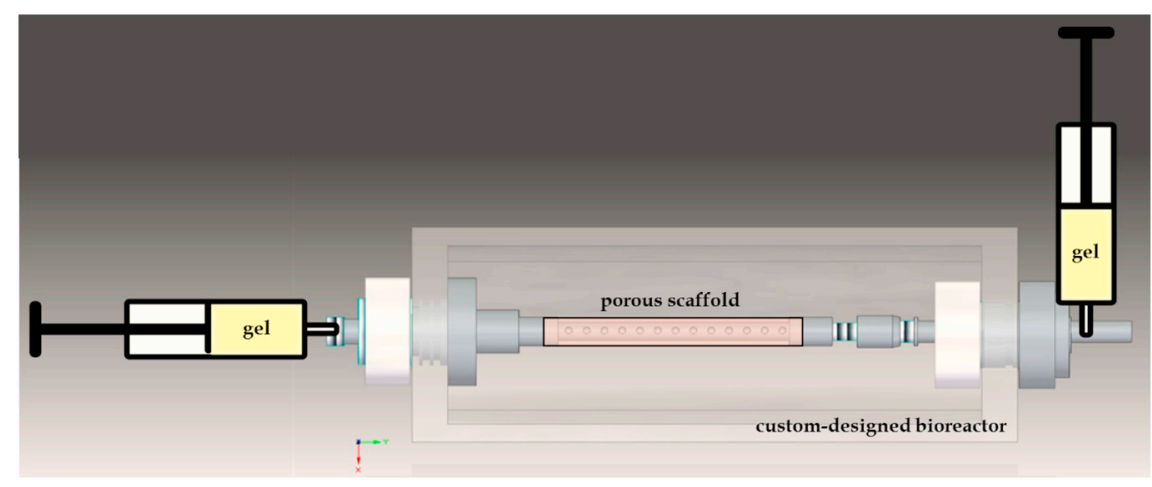

Fig. 2. The custom-design bioreactor to produce the tubular alginate/gelatin coating, showing the symmetric injection of the gel and the housing of the porous scaffold. 
A

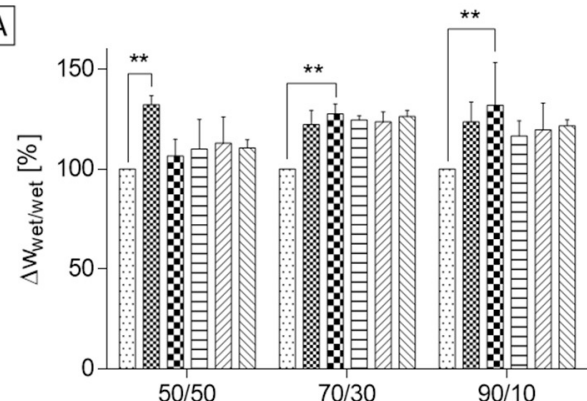

B

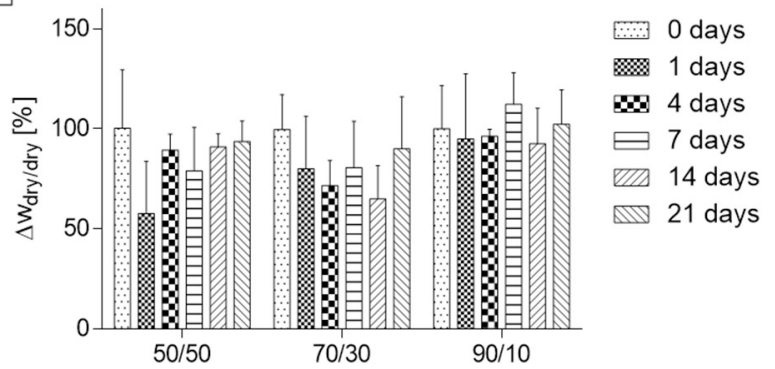

Fig. 3. Swelling and stability of different formulations of Alg/Gel gel (50/50, 70/30, and 90/10). (A) Percentage wet/wet weight variation ( $\Delta w_{\text {wet/wet }}$ ) and (B) Percentage dry/dry weight variation $\left(\Delta w_{d r y} / d r y\right)$ for each time point.

$50 / 50$ after 14 days, and in $70 / 30$ after 7 and 14 days, suggesting a remodeling action of gels by the cultured ECs with ECM synthesis. Regarding torque sweep, $\mathrm{G}^{\prime}$ remained constant up to a shear stress $\tau$ of at least $80 \mathrm{dyne} / \mathrm{cm}^{2}$, with superior rheological properties on both $70 /$ 30 and 90/10 Alg/Gel gels (Fig. 4C-D).

For higher $\tau$, a slow decrease was observed, especially for gels composed by higher amounts of Gel. Therefore, it is suggested that higher amounts of Gel resulted in more brittle gels.

While gels got softer with aging caused by culture conditions (Fig. 4B), $\tau$ stability was retained (Fig. 4C).

\subsubsection{Uniaxial tensile tests}

Uniaxial tensile tests were performed on tubular $\mathrm{Alg} / \mathrm{Gel}$ coated Ortovatt $^{\circledast}$ wadding, with a coating thickness of $2 \mathrm{~mm}$. The $\sigma / \varepsilon$ curves obtained under tension of tubular $\mathrm{Alg} / \mathrm{Gel}$ coated wadding in a wet environment were comparable to wet tubular uncoated wadding. Under uniaxial tension, tubular $\mathrm{Alg} / \mathrm{Gel}$ coated wadding showed a comparable mechanical behavior in the linear region, up to $20 \%$ deformation (Fig. 5A) and Young's modulus among the different formulations (Fig. 5B). Fracture deformation $\varepsilon_{\mathrm{f}, \mathrm{g}}$ of the different formulations of $\mathrm{Alg} /$ Gel gel were significantly ( $<0.05$ ) different, but always bigger than $10 \%$. The gels with intermediate content of $\mathrm{Gel}(70 / 30 \mathrm{Alg} / \mathrm{Gel})$ presented higher $\varepsilon_{\mathrm{f}, \mathrm{g}}$. Either the prevalence of $\mathrm{Gel}$, for $50 / 50 \mathrm{Alg} / \mathrm{Gel}$, or

A

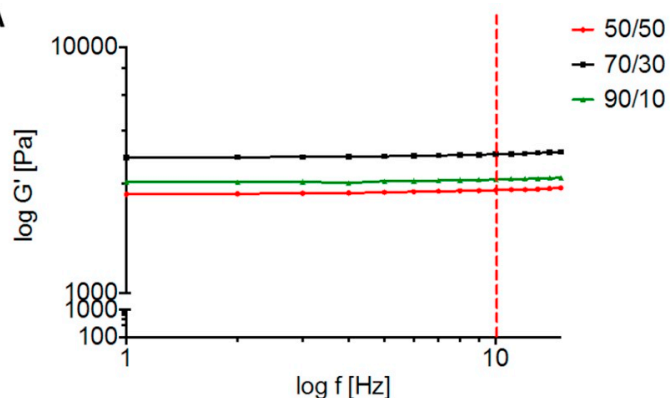

C

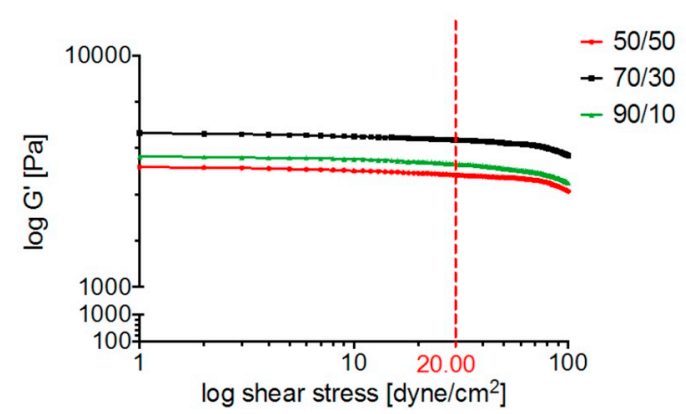

crosslinked $\mathrm{Alg}$, for 90/10 $\mathrm{Alg} / \mathrm{Gel}$, resulted in brittle gels.

\subsubsection{Cell tests}

All $\mathrm{Alg} / \mathrm{Gel}$ gels, either functionalized or not, were able to sustain cell viability (Fig. 6A). Cell number increased after 14 days to about $95 \%, 59 \%$, and $57 \%$ for $50 / 50,70 / 30$, and $90 / 10$, respectively, indicating that cells proliferate in the presence of the tested gels (Fig. 6B). However, cell growth was slower on Alg/Gel gels in comparison to DSA ( $\mathrm{p}<0.05)$, and comparable to Alg gels without Gel $(100 / 0 \mathrm{Alg} / \mathrm{Gel})$ (Fig. 6). Addition of fibronectin enhanced cell viability independently of gel composition ( $\mathrm{p}<0.05$ for all gel compositions at 14 days) (Fig. 6A), although it was not effective in enhancing cell number ( $p>0.05$ for all gel compositions at 14 days) (Fig. 6B). In particular, after 14 days of culture, no significant differences $(\mathrm{p}>0.05)$ could be observed in cell viability for Fn-functionalized 70/30 and 90/10 Alg/ Gel gels and DSA, i.e. the positive control, while the cell number is lower than on DSA.

Interestingly, optical observation (Fig. 6C) showed cells penetrating within the gel thickness, phenomenon amplified when Gel percentage increases, as cells could be focused at different depths within the gels.

Optical observation at 14 days suggests that EA.hy926 cells proliferate on gels. Cells on gels without Fn were mostly rounded-shaped, while the addition of Fn promoted more elongated shapes likely due to

B

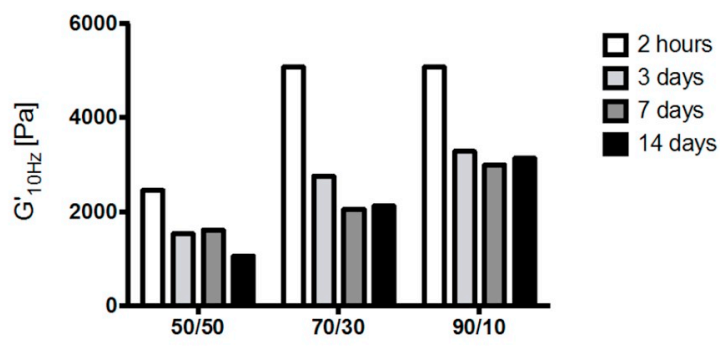

D

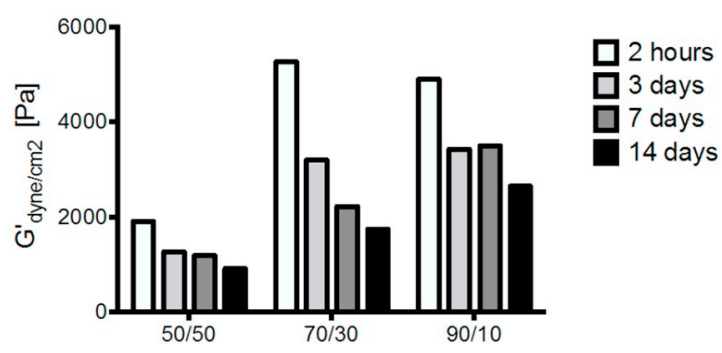

Fig. 4. (A) Representative $\mathrm{G}^{\prime}$ of frequency sweep as a function of $\mathrm{f}[\mathrm{Hz}]$ for 50/50, 70/30, and 90/10 Alg/Gel gels without EA.hy926. (B) Histogram of $\mathrm{G}^{\prime}$ [Pa] at $10 \mathrm{~Hz}$ for 50/50, 70/30, and 90/10 Alg/Gel gels with EA.hy926. (C) Representative $\mathrm{G}^{\prime}$ of torque sweep as a function of $\tau$ [dyne/ $\mathrm{cm}^{2}$ ] for 50/50, 70/30, and 90/10 $\mathrm{Alg} / \mathrm{Gel}$ gels without EA.hy926. (D) Histogram of $\mathrm{G}^{\prime}[\mathrm{Pa}]$ at 20 dyne/ $\mathrm{cm}^{2}$ for 50/50, 70/30, and 90/10 Alg/Gel gels with EA.hy926. 

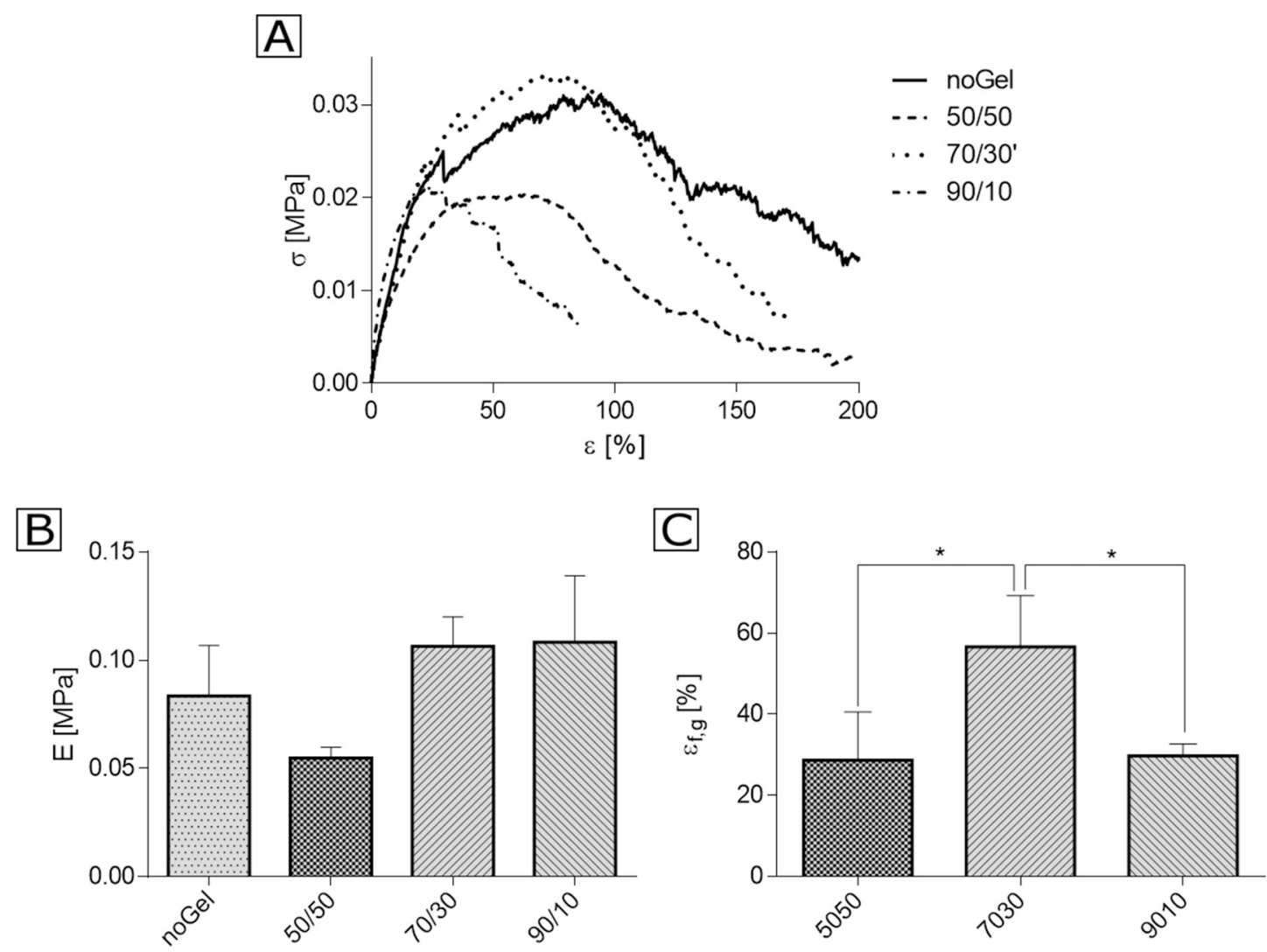

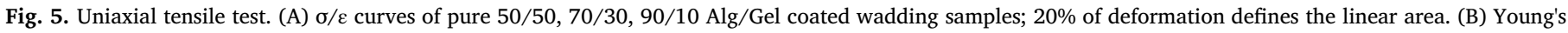

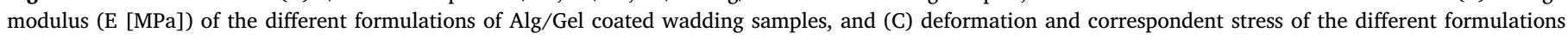
of $\mathrm{Alg} / \mathrm{Gel}$ coated wadding samples ( $\varepsilon_{\mathrm{f}, \mathrm{g}}$ and $\sigma_{\mathrm{f}, \mathrm{g}}$ respectively).

the interaction with the adhesive moieties of Fn [52] (Fig. 6C). Nevertheless, the tendency of cells to form cellular clusters was maintained in all gels, in particular for 100/0 and 100/0 + Fn gels. Cells on Fn-functionalized gels created connections and communications with surrounding ECs, especially in 50/50 Alg/Gel gels. On the overall, although fibronectin adsorbed onto the surface of the hydrogels was effective in modifying the cellular response, the stability of the coating and the interaction with the hydrogels should be further elucidated.

\subsection{Production of the tubular alginate/gelatin coating}

To create the homogenous tubular coating on the luminal surface of porous tubular scaffolds, the InBreath ${ }^{\circledast}$ Bioreactor was modified, using its double advantage of the luminal seeding and of the longitudinal rotation [48]. The reached objectives of the InBreath $^{\circledast}$ modifications consisted on: (1) symmetric injection of the gel through the lateral accesses, (2) ability to mount tubular scaffolds with variable length (from a minimum of $32 \mathrm{~mm}$ to a maximum of $65 \mathrm{~mm}$ ), and (3) inner diameter of the scaffold less or equal to $5 \mathrm{~mm}$, thus suitable for smallcaliber VTE. The global vision of the modified bioreactor is depicted in Fig. 7A. The diameter of the scaffold holders was decreased from 12 to $7 \mathrm{~mm}$ (Fig. 7B). The lateral access on the same side of the rotative motor was modified, by producing a cylindrical arbor $\left(\varnothing_{\text {int }}=2.5 \mathrm{~mm}\right.$, $\emptyset_{\text {ext }}=5 \mathrm{~mm}$ ) with a luer-lock connection on the external side to inject the gel solution (Fig. 7C). The mandrel was modified to reach $65 \mathrm{~mm}$ in length, was drilled every $0.5 \mathrm{~mm}$ with $0.1-\mathrm{mm}$ holes to ensure a uniform gel distribution along the mandrel, and ended with a threaded part to join with the arbor; the mandrel diameter was reduced from 6 to $5 \mathrm{~mm}$ with an inner diameter of $2.5 \mathrm{~mm}$. To fit tubular scaffolds with different length, some scaffold holders were designed as cylindrical pieces made by a smooth part to cover the mandrel holes and a screw part to fix the holder to the mandrel (Fig. 7D). Finally, a screw coupling was studied to link the scaffold holder to the arbor using a Luer-lock connection to allow a stable rotational movement in both clockwise and counterclockwise directions (Fig. 7E).

Optical investigations of 50/50, 70/30, and 90/10 Alg/Gel coating on tubular wadding demonstrated the effectiveness of the modifications in the InBreath ${ }^{\circledast}$ Bioreactor to create a uniform and a homogenous gel coating into tubular structures, independently of gel composition (Fig. 8A-C). The gel formation kinetics allowed the crosslinking process inside the bioreactor system, with the uniform leakage of the gel solution throughout the holes of the mandrel before the viscosity increases. The different Alg content, that is related to the crosslinking degree, did not alter the homogeneous distribution of the gel throughout the scaffold lumen. The method was effective to produce a double-layered structure, with an external porous structure and a luminal gel layer (Fig. 8D).

Furthermore, the application of a longitudinal rotation at $5 \mathrm{rpm}$ during the gelation process resulted in the gel permeation through the fibers and occluded pores.

Considering the reported features described on section 3.1 $70 / 30+\mathrm{Fn} \mathrm{Alg} / \mathrm{Gel}$ gel was selected as the main candidate to produce a coating able to leakproof tubular porous scaffolds. Besides exhibiting intermediate properties between 50/50 + Fn and 90/10 + Fn Alg/Gel gels, $70 / 30 \mathrm{Alg} / \mathrm{Gel}$ gels presented higher fracture deformation $\varepsilon_{\mathrm{f}, \mathrm{g}}$ $(\sim 56.61 \%)$, more than twice higher than the deformation to which blood vessels are subjected. Additionally, cell colonization and degradation of $70 / 30+$ Fn started later in comparison to $50 / 50+\mathrm{Fn} \mathrm{Alg} / \mathrm{Gel}$ gels, thus allowing cells to proliferate and then occlude the pores of the tubular scaffold. Therefore, subsequent permeability tests on 70/30 + Fn Alg/Gel coated wadding were performed. 
A
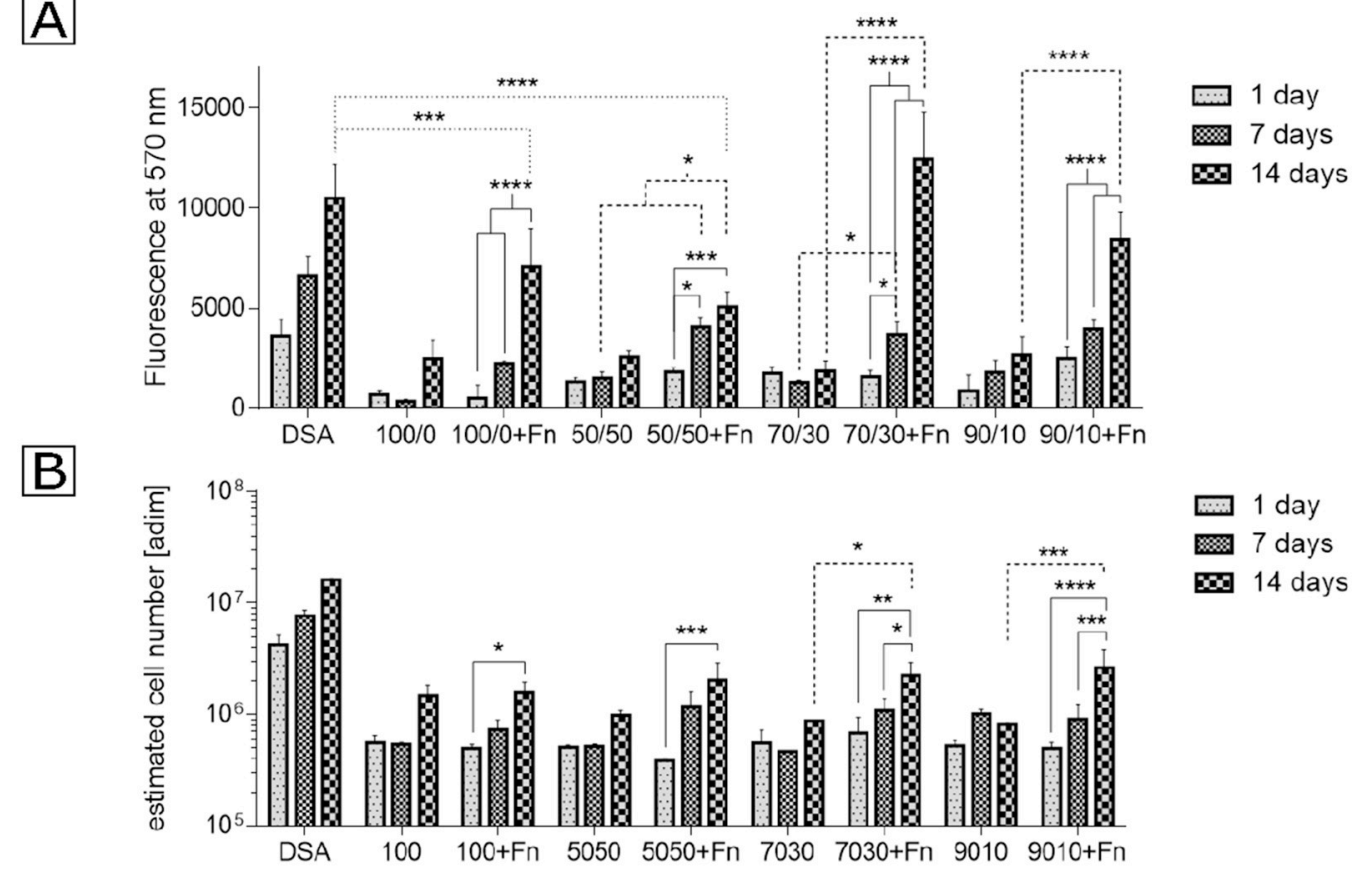

C
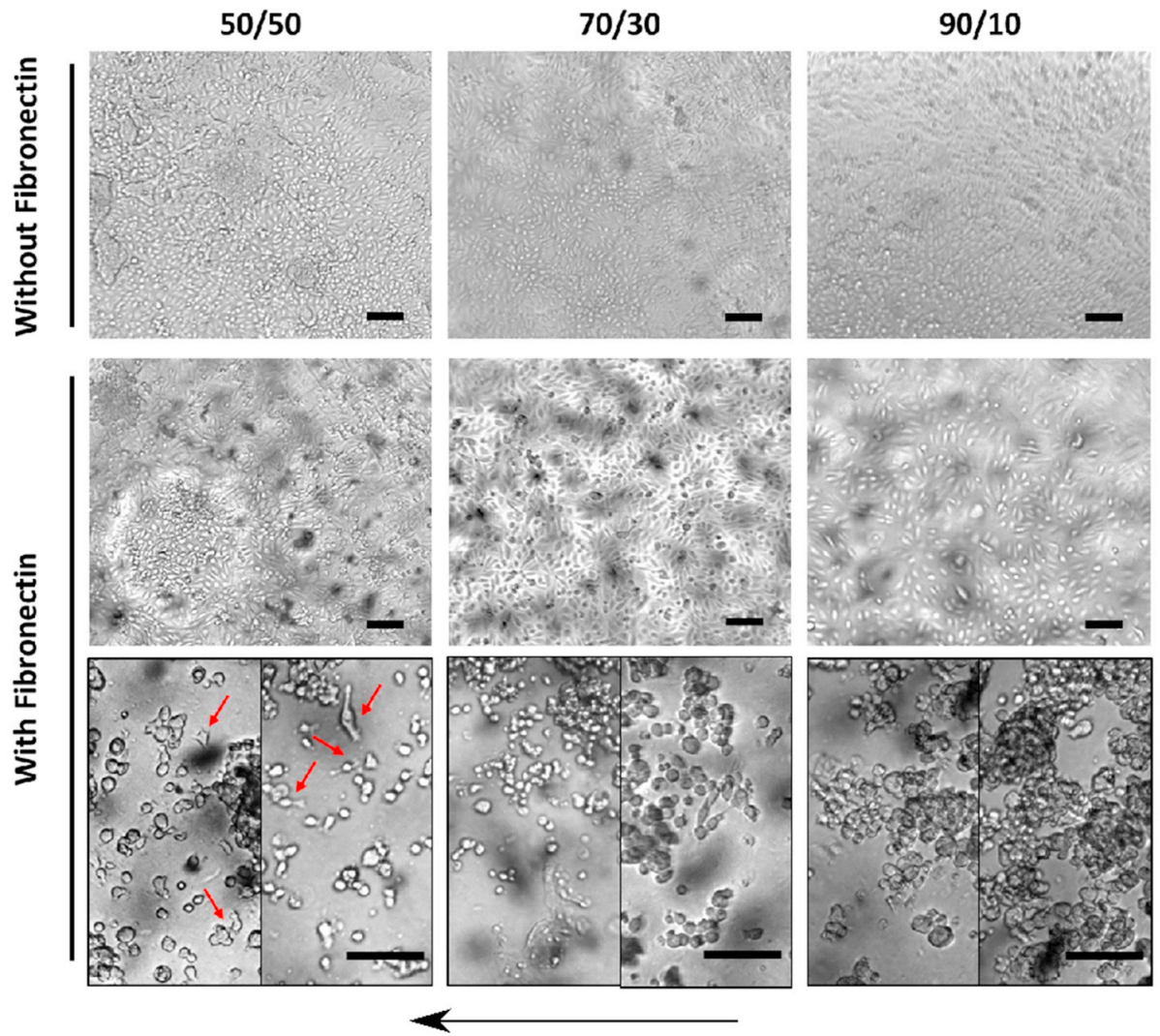

Fig. 6. (A) Viability by resazurin assay and (B) estimated cell number by DNA quantification for 50/50, 70/30, 90/10, 50/50 + Fn, 70/30 + Fn, and 90/10 + Fn $\mathrm{Alg} / \mathrm{Gel}$ gels in comparison to DSA (positive control). (C) Images by optical microscope of cells after 14 days of static culture. Red arrows indicate areas where ECs create connections with other ECs. Cell spreading is augmented in the direction of the black arrow, as Gel percentage increases. Bar of $500 \mu \mathrm{m}$. (For interpretation of the references to color in this figure legend, the reader is referred to the web version of this article.)

\subsection{Permeability assessment of tubular 70/30-coated wadding}

The permeability $\left(\mathrm{K}_{\text {Darcy }}\right.$ ) of electrospun silk fibroin, 70/30 + Fn $\mathrm{Alg} / \mathrm{Gel}$ coated wadding, and DSA, calculated according to Eq. (6), were comparable but highly different in comparison to pure wadding
(Fig. 9A). The gel coating $(70 / 30+\mathrm{Fn} \mathrm{Alg} / \mathrm{Gel})$ could occlude the pores of the material and therefore achieving leakproof tubular structures. This is also confirmed by Fig. 9B where it can be observed that the bioreactor chamber is empty of fluid both for 70/30 + Fn Alg/gel coated wadding and DSA at the end of permeability test; on the 

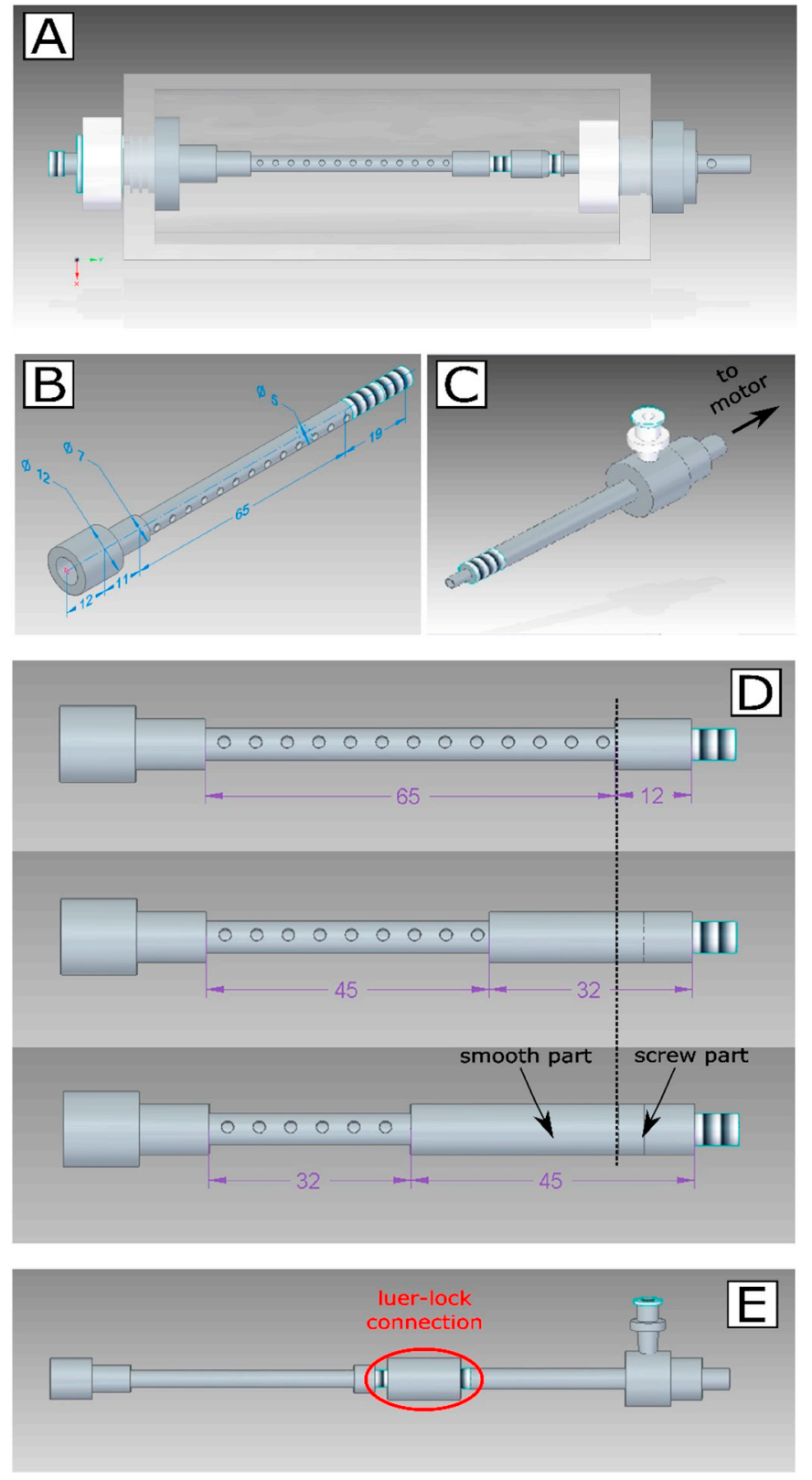

Fig. 7. Automatized Alginate/Gelatin Coating System. (A) The custom-made bioreactor in an assembled configuration. (B) Details of the mandrel in terms of diameter and length. (C) Arbor with the Luer-lock connector (white) to inject the gel solution. (D) Different length of the scaffold holders to house scaffolds from diverse lengths, and (E) Lateral vision of both mandrel and arbor in connected configuration thanks to the Luer-lock connector (red circle) that allows the longitudinal rotation in both directions. (For interpretation of the references to color in this figure legend, the reader is referred to the web version of this article.) contrary, the bioreactor chamber was completely fulfilled, strengthening the leakproofing role played by the gel coating.

\section{Discussion and conclusions}

In this work, a functionalized $\mathrm{Alg} / \mathrm{Gel}$ coating was engineered aiming to leakproof tubular porous scaffolds for small-caliber vessel tissue engineering and obtain a graded structure where the inner layer possesses different properties although being intimately connected to the outer layer. A fully automatized method was established, by exploiting the use of bioreactor for processing purposes, producing a homogeneous coating of a tubular substrate to selectively coat the luminal surface. The formulation of the gels allowed compatible kinetics with the formation of a uniform inner coating.

Gels demonstrated their ability to well withstand to shear stress within the range of $5-20$ dyne $/ \mathrm{cm}^{2}$ (Fig. 4C), ensuring their suitability for vascular tissue engineering application [5]. The obtained results are consistent with the experienced physiological fluid wall shear stress to which endothelial cells are stimulated, and that ensures the requirement for the maintenance of their phenotype and consequently antiinflammatory conditions [53]. Even if the shear stress imposed by the rheometer is due to rotation instead of sliding or flow effect, rheological tests under torque sweep can indirectly provide an insight of gel resistance under shear stress because of the anisotropic inner structure of the gels, caused by the random crosslinking/gelation process.

Mass transport through the vessel wall is a complex phenomenon, with different key features to be addressed, and the cellular components play an active role. Molecular diffusion depends on interactions with the ECM molecules, active transport, metabolic activity and phase changes, dimensions, and chemistry of the molecules to be transported. In our work, we limit the study on modeling fluid transport, as a proof of concept about the fluid permeability of the construct.

The Darcy's permeability coefficient of the 70/30 Alg/Gel coated wadding are comparable to values reported in the literature, in the range of $1.2 \times 10^{-16}$ to $3 \times 10^{-12} \mathrm{~m}^{2}$, valid for decellularized arteries, human umbilical veins, and synthetic porous scaffolds, such as polycaprolactone, silk fibroin, and PGA with PLA copolymers [54-57]. This evidence confirms the coating was efficient to prevent leakage under low-pressure flow $(16 \mathrm{mmHg})$ and shear stress of about 25 dyne $/ \mathrm{cm}^{2}$. However, at high-pressure condition $(120 \mathrm{mmHg})$ the effect of pressureenlarged nanoporosity of the Alg/Gel gel may affect Darcy's permeability coefficient [58]. Additionally, the phenomenon of gel degradation coupled with simultaneous ECM synthesis by EA.hy926 could also alter and modify the transmural fluid leakage, making the leakproofing properties variable throughout the culture [59]. The design of the scaffold itself can be exploited to modify mass transport by the alternating double-phase exposure of cell-seeded scaffolds, alternately halfimmersed into the culture medium and half-exposed to air thanks to longitudinal rotation $[28,48,60]$. In this case, the convective phenomenon is used together with molecules diffusion into the fluid (culture medium), accordingly to the equation of mass transport.

$\mathrm{Alg} / \mathrm{Gel}$ gels were stable (Fig. 3), independently of the hydrogel composition, in the cell culture medium. Although monovalent ions, $\mathrm{Na}^{+}$and $\mathrm{K}^{+}$, are present in DMEM, the compensating activity of
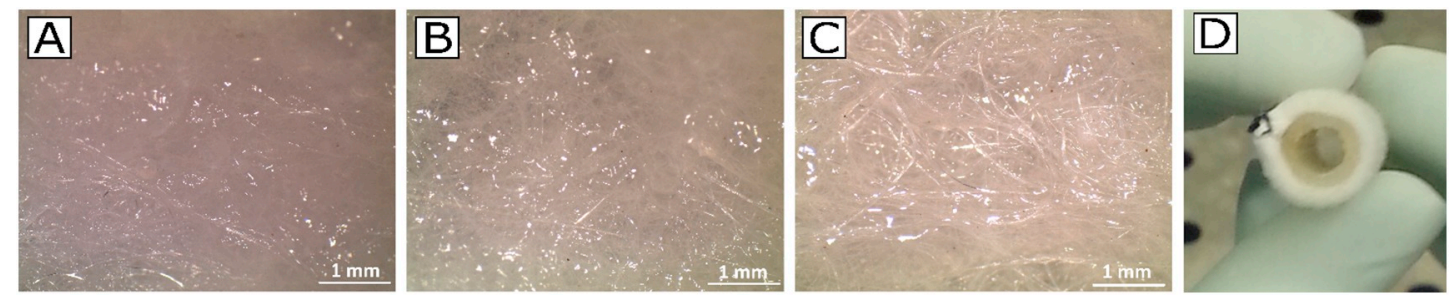

Fig. 8. Tubular coating of (A) 50/50, (B) 70/30, and (C) 90/10 obtained by using the modified InBreath Bioreactor. (D) Section of the gel-coating tubular wadding scaffold. The luminal coating is uniform and homogeneous. 

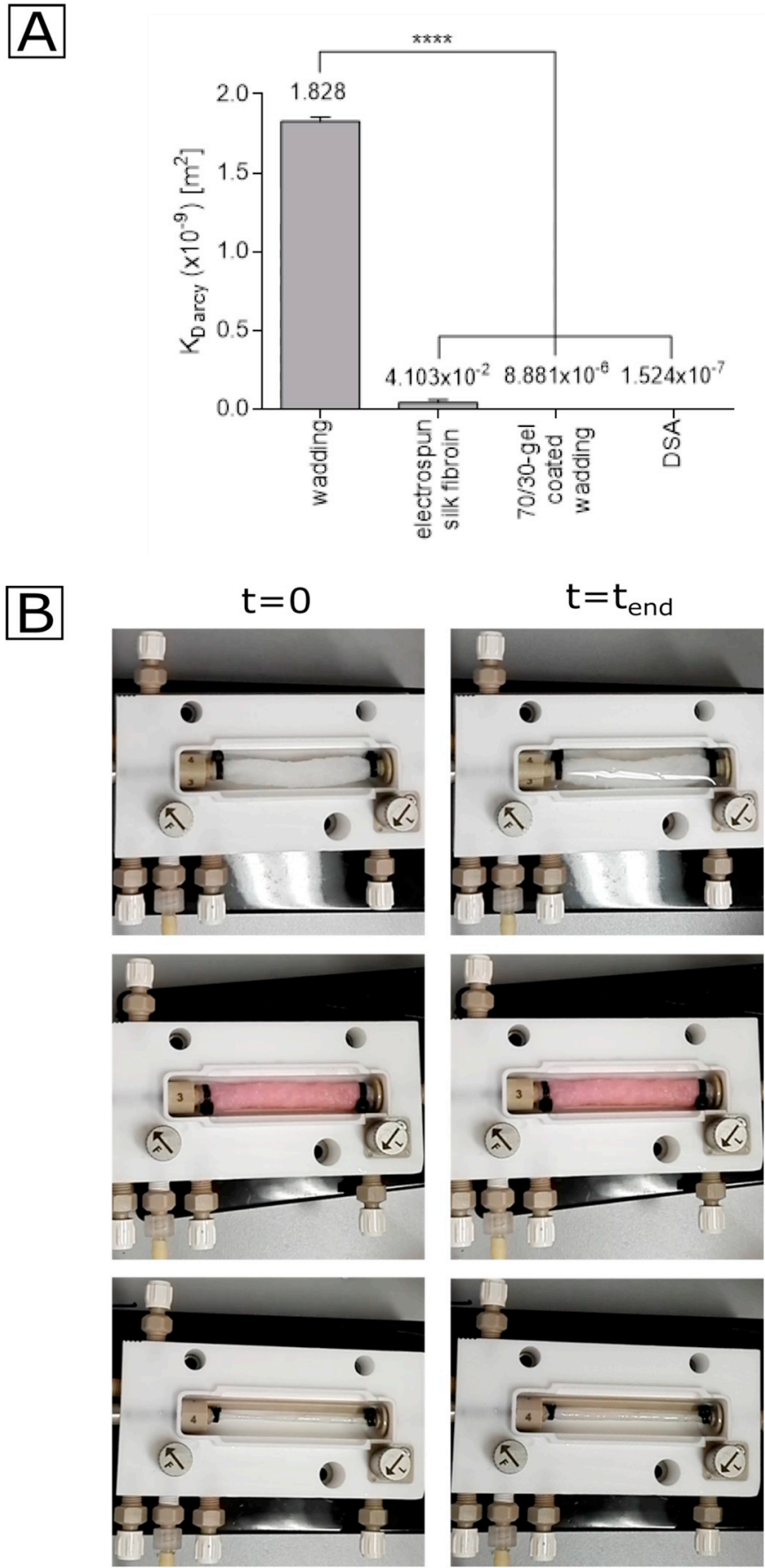

Fig. 9. (A) Permeability coefficient $\left(\mathrm{K}_{\text {Darcy }}\right)$ of the considered materials: wadding, electrospun silk fibroin, 70/30-gel coated wadding, and decellularized swine artery (DSA), at mean working pressure of $16 \mathrm{mmHg}$ and shear stress of $25 \mathrm{dyne} / \mathrm{cm}^{2}$. (B) Images of the bioreactor setup during the permeability test at the beginning of the test $(t=0)$ and at the end of the measurement $\left(t=t_{\text {end }}\right.$, where $t_{\text {end }}$ is the corresponding time when the fluid completely fulfills the bioreactor chamber).

plurivalent ions present in calcium chloride, ferric nitrate, magnesium sulfate prevent $\mathrm{Ca}^{++}$displacement from the egg-box crosslinked network, thus preventing dissolution. Gelatin does not alter this mechanism, and no effect of the introduction of gelatin can be observed on the stability of the hydrogels in our testing conditions. Rheological tests, uniaxial tension, and direct cytotoxicity evidenced the specific role played by Alg and Gel into the gel structure. The rheological properties during cell culture (Fig. 4B and D) mainly decreased for the higher content of Gel possibly by a contribution in the loss of rheological properties that could be ascribed to cell remodeling of the scaffold upon ECs colonization of the gel (Fig. 4B). Along culture period, ECs start to synthesize ECM, as suggested by higher $\mathrm{G}^{\prime}$ in $50 / 50$ and 70/30 $\mathrm{Alg} / \mathrm{Gel}$ after 7 days of culture (Fig. 4B).

Cells partially degraded the gel itself independently of gel formulation probably due to the action of matrix metalloproteinases (MMPs), such as MMP-2 and MMP-9 [59,61], since softer and degraded gels were evidenced during the culture (Fig. 6C), phenomenon especially pronounced for higher amounts of Gel.

Interestingly, 70/30 Alg/Gel gel presented a significantly higher $\varepsilon_{\mathrm{f}, \mathrm{g}}$. The intermediate composition, 70/30 Alg/Gel, may take advantage of the presence of Alg network where Gel chains are interpenetrated, inducing a plasticizing effect (Fig. 5C). This deformation value is five times bigger than the physiological deformation $(\sim 10 \%)$ to which blood vessels are subjected in vivo [5], ensuring the presence of a wider security region within 70/30 $\mathrm{Alg} / \mathrm{Gel}$ gel works before the fracture, although a fatigue test could be also necessary since the scaffold will be subjected to a cyclic load (pulsatile perfusion).

In conclusion, coupling these promising Fn-functionalized $\mathrm{Alg} / \mathrm{Gel}$ gels with the experimental method to create uniform tubular gel coatings, we were able to uniformly cover the luminal surface of porous scaffolds, reaching two main goals: (1) the reduction of medium leakage through its pores, allowing the perfusion of the scaffold with known flow rates, and (2) the confinement of ECs to the luminal layer of the double-structured scaffold, potentially providing a scaffold able to reproduce the anatomic structure of blood vessels. A double-layered leakproofing porous tubular scaffold was therefore developed as a scaffold for small-caliber VTE.

\section{Acknowledgments}

We thank dott. Stefano Lorenzoni by Leonardino Srl, MG design management srl to provide us tubular electrospun silk fibroin for permeability test.

\section{Funding}

This research did not receive any specific grant from funding agencies in the public, commercial, or not-for-profit sectors.

\section{Appendix A. Supplementary data}

Supplementary data to this article can be found online at https:// doi.org/10.1016/j.msec.2019.110035.

\section{References}

[1] A.E. Moran, G.A. Roth, J. Narula, G.A. Mensah, 1990-2010 global cardiovascular disease atlas, Glob. Heart 9 (2014) 3-16, https://doi.org/10.1016/j.gheart.2014. 03.1220 .

[2] D. Mozaffarian, E.J. Benjamin, A.S. Go, D.K. Arnett, M.J. Blaha, M. Cushman, et al., Heart disease and stroke statistics-2016 update: a report from the American Heart Association, Circulation 133 (2016) e38-e360, https://doi.org/10.1161/CIR. 0000000000000350.

[3] J. Chlupac, E. Filova, L. Bacakova, Blood vessel replacement: 50 years of development and tissue engineering paradigms in vascular surgery, Physiol. Res. 58 (Suppl. 2) (2009) S119-S139.

[4] C.K. Prasad, L.K. Krishnan, Regulation of endothelial cell phenotype by biomimetic matrix coated on biomaterials for cardiovascular tissue engineering, Acta Biomater. 4 (2008) 182-191, https://doi.org/10.1016/j.actbio.2007.05.012.

[5] C. Tresoldi, A.F. Pellegata, S. Mantero, Cells and stimuli in small-caliber blood vessel tissue engineering, Regen. Med. 10 (2015) 505-527, https://doi.org/10. 2217/rme.15.19.

[6] M.A. Asnaghi, G. Candiani, S. Fare, G.B. Fiore, P. Petrini, M.T. Raimondi, et al., Trends in biomedical engineering: focus on regenerative medicine, J Appl Biomater Biomech 9 (2011) 73-86, https://doi.org/10.5301/JABB.2011.8562.

[7] S. Mantero, N. Sadr, S.A. Riboldi, S. Lorenzoni, F.M. Montevecchi, A new electromechanical bioreactor for soft tissue engineering, J Appl Biomater Biomech 5 (2007) 107-116.

[8] J.S. Uzarski, J. Cores, P.S. McFetridge, Physiologically modeled pulse dynamics to 
improve function in in vitro-endothelialized small-diameter vascular grafts, Tissue Eng Part C Methods 21 (2015) 1125-1134, https://doi.org/10.1089/ten.TEC.2015. 0110 .

[9] Z. Gong, L.E. Niklason, Small-diameter human vessel wall engineered from bone marrow-derived mesenchymal stem cells (hMSCs), FASEB J. 22 (2008) 1635-1648, https://doi.org/10.1096/fj.07-087924.

[10] J. Zeltinger, J.K. Sherwood, D.A. Graham, R. Mueller, L.G. Griffith, Effect of pore size and void fraction on cellular adhesion, proliferation, and matrix deposition, Tissue Eng. 7 (2001) 557-572, https://doi.org/10.1089/107632701753213183.

[11] X. Yang, L. Wang, G. Guan, H. Zhang, G. Shen, Y. Guan, et al., Mechanical and biocompatibility performance of bicomponent polyester/silk fibroin small-diameter arterial prostheses, J Appl Biomater Funct Mater 13 (2015) e201-e209, https://doi. org $/ 10.5301 / \mathrm{jabfm} .5000225$.

[12] L. Sardelli, D.P. Pacheco, L. Zorzetto, C. Rinoldi, W. Swieszkowski, P. Petrini, Engineering biological gradients, J Appl Biomater Funct Mater 17 (2019), https:// doi.org/10.1177/2280800019829023 2280800019829023.

[13] S. Tara, K.A. Rocco, N. Hibino, T. Sugiura, H. Kurobe, C.K. Breuer, et al., Vessel bioengineering, Circ. J. 78 (2014) 12-19.

[14] F. Khoffi, D. Mathieu, F. Dieval, N. Chakfe, B. Durand, Compliance properties of collagen-coated polyethylene terephthalate vascular prostheses, J Appl Biomater Funct Mater 12 (2014) 163-171, https://doi.org/10.5301/jabfm.5000189.

[15] G. De Visscher, L. Mesure, B. Meuris, A. Ivanova, W. Flameng, Improved en dothelialization and reduced thrombosis by coating a synthetic vascular graft with fibronectin and stem cell homing factor SDF-1alpha, Acta Biomater. 8 (2012) 1330-1338, https://doi.org/10.1016/j.actbio.2011.09.016.

[16] L.A. Dudash, F. Kligman, S.M. Sarett, K. Kottke-Marchant, R.E. Marchant, Endothelial cell attachment and shear response on biomimetic polymer-coated vascular grafts, J. Biomed. Mater. Res. A 100 (2012) 2204-2210, https://doi.org/ 10.1002/jbm.a.34119.

[17] X. Ren, Y. Feng, J. Guo, H. Wang, O. Li, J. Yang, et al., Surface modification and endothelialization of biomaterials as potential scaffolds for vascular tissue engineering applications, Chem. Soc. Rev. 44 (2015) 5680-5742 (doi 10.1039/ c4cs00483c).

[18] A.J. Melchiorri, L.G. Bracaglia, L.K. Kimerer, N. Hibino, J.P. Fisher, In vitro endothelialization of biodegradable vascular grafts via endothelial progenitor cell seeding and maturation in a tubular perfusion system bioreactor, Tissue Eng Part C Methods 22 (2016) 663-670, https://doi.org/10.1089/ten.TEC.2015.0562.

[19] W.S. Sheridan, G.P. Duffy, B.P. Murphy, Mechanical characterization of a customized decellularized scaffold for vascular tissue engineering, J. Mech. Behav. Biomed. Mater. 8 (2012) 58-70, https://doi.org/10.1016/j.jmbbm.2011.12.003.

[20] Y. Xin, G. Wu, M. Wu, X. Zhang, E. Velot, V. Decot, et al., Construction of biocompatible porous tissue scaffold from the decellularized umbilical artery, Biomed Mater Eng 25 (2015) 65-71, https://doi.org/10.3233/BME-141261.

[21] A.F. Pellegata, M.A. Asnaghi, I. Stefani, A. Maestroni, S. Maestroni, T. Dominioni, et al., Detergent-enzymatic decellularization of swine blood vessels: insight on mechanical properties for vascular tissue engineering, Biomed. Res. Int. 2013 (2013) 918753, https://doi.org/10.1155/2013/918753.

[22] J. Daniel, K. Abe, P.S. McFetridge, Development of the human umbilical vein scaffold for cardiovascular tissue engineering applications, ASAIO J. 51 (2005) $252-261$.

[23] S.K. Yazdani, B. Watts, M. Machingal, Y.P. Jarajapu, M.E. Van Dyke, G.J. Christ, Smooth muscle cell seeding of decellularized scaffolds: the importance of bioreactor preconditioning to development of a more native architecture for tissue-engineered blood vessels, Tissue Eng Part A 15 (2009) 827-840, https://doi.org/10.1089/ten. tea.2008.0092.

[24] K. Youssef, J.J. Mack, M.L. Iruela-Arispe, L.S. Bouchard, Macro-scale topology optimization for controlling internal shear stress in a porous scaffold bioreactor, Biotechnol. Bioeng. 109 (2012) 1844-1854, https://doi.org/10.1002/bit.24440.

[25] A. Atala, Engineering organs, Curr. Opin. Biotechnol. 20 (2009) 575-592, https:// doi.org/10.1016/j.copbio.2009.10.003.

[26] J.E. McBane, S. Sharifpoor, R.S. Labow, M. Ruel, E.J. Suuronen, J.P. Santerre, Tissue engineering a small diameter vessel substitute: engineering constructs with select biomaterials and cells, Curr. Vasc. Pharmacol. 10 (2012) 347-360.

[27] I. Bruzauskaite, D. Bironaite, E. Bagdonas, E. Bernotiene, Scaffolds and cells for tissue regeneration: different scaffold pore sizes-different cell effects, Cytotechnology 68 (2016) 355-369, https://doi.org/10.1007/s10616-015-9895-4.

[28] C. Tresoldi, I. Stefani, G. Ferracci, S. Bertoldi, A.F. Pellegata, S. Fare, et al., Alternating air-medium exposure in rotating bioreactors optimizes cell metabolism in 3D novel tubular scaffold polyurethane foams, J Appl Biomater Funct Mater 15 (2017) e122-e132, https://doi.org/10.5301/jabfm.5000334.

[29] T. Al Kayal, D. Maniglio, W. Bonani, P. Losi, C. Migliaresi, G. Soldani, A combined method for bilayered vascular graft fabrication, J Mater Sci Mater Med 26 (2015) 96, https://doi.org/10.1007/s10856-015-5458-7.

[30] Y.M. Ju, J.S. Choi, A. Atala, J.J. Yoo, S.J. Lee, Bilayered scaffold for engineering cellularized blood vessels, Biomaterials 31 (2010) 4313-4321, https://doi.org/10. 1016/j.biomaterials.2010.02.002.

[31] A. Mathews, S. Colombus, V.K. Krishnan, L.K. Krishnan, Vascular tissue construc tion on poly(epsilon-caprolactone) scaffolds by dynamic endothelial cell seeding: effect of pore size, J. Tissue Eng. Regen. Med. 6 (2012) 451-461 doi https://doi. org/10.1002/term.449.

[32] S. Bozzini, L. Giuliano, L. Altomare, P. Petrini, A. Bandiera, M.T. Conconi, et al., Enzymatic cross-linking of human recombinant elastin (HELP) as biomimetic approach in vascular tissue engineering, J Mater Sci Mater Med 22 (2011) 2641-2650, https://doi.org/10.1007/s10856-011-4451-z.

[33] S. Afewerki, A. Sheikhi, S. Kannan, S. Ahadian, A. Khademhosseini, Gelatin-polysaccharide composite scaffolds for 3D cell culture and tissue engineering: towards natural therapeutics, Bioeng Transl Med 4 (2019) 96-115, https://doi.org/10. 1002/btm2.10124.

[34] Y. Elsayed, C. Lekakou, P. Tomlins, Modeling, simulations, and optimization of smooth muscle cell tissue engineering for the production of vascular grafts, Biotechnol. Bioeng. 116 (2019) 1509-1522, https://doi.org/10.1002/bit.26955.

[35] A.A. Aldana, G.A. Abraham, Current advances in electrospun gelatin-based scaffolds for tissue engineering applications, Int. J. Pharm. 523 (2017) 441-453, https://doi. org/10.1016/j.ijpharm.2016.09.044.

[36] 722/2012 CREN, Commission Regulation (EU) No 722/2012 of 8 August 2012 concerning particular requirements as regards the requirements laid down in Council Directives 90/385/EEC and 93/42/EEC with respect to active implantable medical devices and medical devices manufactured utilizing tissues of animal origin, Off. J. Eur. Union (2012) August. (L 212/3).

[37] G.D. Nicodemus, S.J. Bryant, Cell encapsulation in biodegradable hydrogels for tissue engineering applications, Tissue Eng Part B Rev 14 (2008) 149-165, https:// doi.org/10.1089/ten.teb.2007.0332.

[38] A.W. Chan, R.J. Neufeld, Tuneable semi-synthetic network alginate for absorptive encapsulation and controlled release of protein therapeutics, Biomaterials 31 (2010) 9040-9047, https://doi.org/10.1016/j.biomaterials.2010.07.111.

[39] C.K. Kuo, P.X. Ma, Ionically crosslinked alginate hydrogels as scaffolds for tissue engineering: part 1. Structure, gelation rate and mechanical properties, Biomaterials 22 (2001) 511-521.

[40] A. Vedadghavami, F. Minooei, M.H. Mohammadi, S. Khetani, A. Rezaei Kolahchi, S. Mashayekhan, et al., Manufacturing of hydrogel biomaterials with controlled mechanical properties for tissue engineering applications, Acta Biomater. 62 (2017) 42-63, https://doi.org/10.1016/j.actbio.2017.07.028.

[41] T. Andersen, P. Auk-Emblem, M. Dornish, 3D cell culture in alginate hydrogels, Microarrays (Basel) 4 (2015) 133-161, https://doi.org/10.3390/ microarrays4020133.

[42] S.J. Bidarra, C.C. Barrias, P.L. Granja, Injectable alginate hydrogels for cell delivery in tissue engineering, Acta Biomater. 10 (2014) 1646-1662, https://doi.org/10. 1016/j.actbio.2013.12.006.

[43] F.R. Maia, K.B. Fonseca, G. Rodrigues, P.L. Granja, C.C. Barrias, Matrix-driven formation of mesenchymal stem cell-extracellular matrix microtissues on soft alginate hydrogels, Acta Biomater. 10 (2014) 3197-3208, https://doi.org/10.1016/j actbio.2014.02.049.

[44] E. Secchi, F. Munarin, M.D. Alaimo, S. Bosisio, S. Buzzaccaro, G. Ciccarella, et al., External and internal gelation of pectin solutions: microscopic dynamics versus macroscopic rheology, J Phys Condens Matter 26 (2014) 464106, , https://doi.org/ 10.1088/0953-8984/26/46/464106.

[45] H.R. Moreira, F. Munarin, R. Gentilini, L. Visai, P.L. Granja, M.C. Tanzi, et al., Injectable pectin hydrogels produced by internal gelation: $\mathrm{pH}$ dependence of gelling and rheological properties, Carbohydr. Polym. 103 (2014) 339-347, https://doi. org/10.1016/j.carbpol.2013.12.057.

[46] W.M. Kulicke, C. Clasen, Viscosimetry of Polymers and Polyelectrolytes 120 Springer Science \& Business Media, 2013

[47] S.K. Williams, A.W. Sasaki, M.A. Matthews, R.C. Wagner, Quantitative determination of deoxyribonucleic acid from cells collected on filters, Anal. Biochem. 107 (1980) 17-20.

[48] M.A. Asnaghi, P. Jungebluth, M.T. Raimondi, S.C. Dickinson, L.E. Rees, T. Go, et al., A double-chamber rotating bioreactor for the development of tissue-engineered hollow organs: from concept to clinical trial, Biomaterials 30 (2009) 5260-5269, https://doi.org/10.1016/j.biomaterials.2009.07.018.

[49] A.F. Pellegata, T. Dominioni, F. Ballo, S. Maestroni, M.A. Asnaghi, G. Zerbini, et al., Arterial decellularized scaffolds produced using an innovative automatic system, Cells Tissues Organs 200 (2015) 363-373, https://doi.org/10.1159/000439082.

[50] D. Wang, H. Liu, Y. Fan, Silk fibroin for vascular regeneration, Microsc. Res. Tech. 80 (2017) 280-290, https://doi.org/10.1002/jemt.22532.

[51] E. Figallo, M. Flaibani, B. Zavan, G. Abatangelo, N. Elvassore, Micropatterned biopolymer 3D scaffold for static and dynamic culture of human fibroblasts, Biotechnol. Prog. 23 (2007) 210-216, https://doi.org/10.1021/bp0602092.

[52] S. Shinohara, T. Kihara, S. Sakai, M. Matsusaki, M. Akashi, M. Taya, et al. Fabrication of in vitro three-dimensional multilayered blood vessel model using human endothelial and smooth muscle cells and high-strength PEG hydrogel, J. Biosci. Bioeng. 116 (2013) 231-234, https://doi.org/10.1016/j.jbiosc.2013.02. 013.

[53] A.H. Huang, L.E. Niklason, Engineering of arteries in vitro, Cell. Mol. Life Sci. 71 (2014) 2103-2118, https://doi.org/10.1007/s00018-013-1546-3.

[54] E.M. Campbell, P.A. Cahill, C. Lally, Investigation of a small-diameter decellularised artery as a potential scaffold for vascular tissue engineering; biomechanical evaluation and preliminary cell seeding, J. Mech. Behav. Biomed. Mater. 14 (2012) 130-142, https://doi.org/10.1016/j.jmbbm.2012.06.001.

[55] C.V. Montoya, P.S. McFetridge, Preparation of ex vivo-based biomaterials using convective flow decellularization, Tissue Eng Part C Methods 15 (2009) 191-200, https://doi.org/10.1089/ten.tec.2008.0372.

[56] Y. Wang, P.E. Tomlins, A.G. Coombes, M. Rides, On the determination of Darcy permeability coefficients for a microporous tissue scaffold, Tissue Eng Part C Methods 16 (2010) 281-289, https://doi.org/10.1089/ten.tec.2009.0116.

[57] S.J. Hollister, Scaffold design and manufacturing: from concept to clinic, Adv. Mater. 21 (2009) 3330-3342, https://doi.org/10.1002/adma.200802977.

[58] T. Boontheekul, H.J. Kong, D.J. Mooney, Controlling alginate gel degradation utilizing partial oxidation and bimodal molecular weight distribution, Biomaterials 26 (2005) 2455-2465, https://doi.org/10.1016/j.biomaterials. 2004.06.044.

[59] L.M. Matrisian, The matrix-degrading metalloproteinases, Bioessays 14 (1992) 455-463, https://doi.org/10.1002/bies.950140705.

[60] C. Arrigoni, A. Chitto, S. Mantero, A. Remuzzi, Rotating versus perfusion bioreactor 
for the culture of engineered vascular constructs based on hyaluronic acid, Biotechnol. Bioeng. 100 (2008) 988-997, https://doi.org/10.1002/bit.21828.

[61] T. Ishii, N. Asuwa, Collagen and elastin degradation by matrix metalloproteinases and tissue inhibitors of matrix metalloproteinase in aortic dissection, Hum. Pathol. 31 (2000) 640-646, https://doi.org/10.1053/hupa.2000.7642.

Claudia Tresoldi has a Ph.D in Bioengineering at Politecnico di Milano, Italy, where she earned her Master Degree. Since 2013, she has been working on a project concerning Vascular Tissue Engineering. The aim of her investigation is to develop functional SmallCaliber Vessels able to reproduce the fetal development in vitro by coupling different technological aspects. The former is based on cell cultures using a rotating pulsatile perfusion bioreactor; the latter consists in studying a gel-based coating to leakproof tubular cell-seeded scaffolds to be perfused by flow rates that ensure physiological stresses, estimated through a scaffold-specific Fluid-Structure Interaction model.

Daniela P. Pacheco currently is a PhD Candidate at Politecnico di Milano, under the supervision of Prof. Paola Petrini. She has been working on different subjects related to biomaterial science and technology and drug delivery. Her research experience ranges from surface chemistry, micro and nanofabrication techniques, drug delivery systems (micro/nanoparticles and hydrogels) to engineered tissue models for drug screening. Her current research is focused on engineering in vitro models for drug screening.

Elisa Formenti obtained her Master Degree in Bioengineering at Politecnico di Milano in 2015 , focusing her thesis work on the leakproofing of tubular porous scaffolds through the design of a specific bioreactor and the synthesis of gel-based coating.

Alessandro Filippo Pellegata (ORCID 0000-0002-5618-4641) obtained his MSc in bioengineering at Politecnico di Milano, Italy in 2010 with a thesis on the decellularisation of blood vessels (Int J Artif Org, 2012). He had his $\mathrm{PhD}$ in the group of Prof. S. Mantero focused on blood vessel tissue engineering and bioreactors development (Biomed Res Int 2013, Cells Tissues Organs 2015). After completion of the PhD, he worked as postdoctoral scientist at Politecnico di Milano on a project aimed at tendon tissue engineering (Eur Cell Mater 2016, Mater Sci Eng C Mater Biol Appl 2017). He then moved to the UCL GOS Institute of Child Health as research associate in Paolo De Coppi's group. His research work is currently focused on whole organ tissue engineering, in particular on the re-endothelialisation of vascular networks (Front Bioeng Biotechnol 2018). He has also interest in the development of bioreactors and decellularisation techniques for the liver (Plos One 2017), the lung and the thymus.

Sara Mantero (ORCID 0000-0002-1264-0465) is currently Associate professor at Politecnico di Milano. Her main research activity is focused on Tissue Engineering and Regenerative Medicine, Bioreactors design and Biomaterials. Lecturer in "Chemical Bioengineering" and "Biotechnological Applications and Bioreactors" at Politecnico di Milano. Winner of the "Start Cup Milano Lombardia 2006" competition. Winner of the "Premio Nazionale Innovazione- 2006 (PNI 2006)" award, with a Business Plan related to the design and development of a bioreactor for autologous bone regenerative medicine. Winner of the "Knowledge Transfer Partnership Award" 2007 organized by the UK Trade \& Investment Organization of the British Consulate General. Contribution to the London Science Museum's centenary celebrations (section "Who am I?") in June 2010 exhibiting the bioreactor used for the first clinical transplantation of tissue engineered airway. She is author of about 50 peer reviewed international papers in the field of biomaterials, tissue engineering and regenerative medicine.

Paola Petrini (ORCID 0000-0002-5081-5254) is Associate professor at Politecnico di Milano. Professor of "Chemical Bioengineering", "Biomaterials", Instrumental Analysis and Biomaterials Laboratory" for the Biomedical Engineering Degree at Politecnico di Milano. Mentor and tutor of numerous Master thesis $(>60)$, many in cooperation with international Universities, two $\mathrm{PhD}$ thesis in Bioengineering and now tutor of a $\mathrm{PhD}$ thesis in Materials Engineering, at Politecnico di Milano.

Her research activity is related mainly to hydrogels, natural polymers and surface modifications for diverse biomedical application. She has 3 patents, now transferred to companies. She authored about 50 peer reviewed papers and book chapters. 